\title{
Will the Orthodontic Profession Disappear?
}

\author{
Jean-François Masse, DMD, MSc, Diplomate, ABDSM
}

Editor-in-Chief Journal of Dental Sleep Medicine Universite Laval, Quebec City, Quebec, Canada

I am not the one saying this! Rather, the person who forecast the disappearance of orthodontists is Dr. Laurent Alexandre, a French physician, in his book about artificial intelligence entitled in French "La guerre des intelligences"1 (which can be loosely translated as "The War of the Intelligences").

Dr. Alexandre writes that an American company from Silicon Valley called Invisalign will use artificial intelligence to provide patients with better adapted orthodontic treatment protocols. In turn, this will very soon make the orthodontic profession irrelevant, just as the job of lamplighter became obsolete when electrical lighting was introduced.

One does not have to agree with his view, but if you consider that Dr. Alexandre is a medical specialist with an MBA from HEC Paris (the Harvard Business School of France) who sold his website, Doctissimo (the French equivalent of WebMD), 12 years ago for 156 million US dollars, he certainly is more a visionary than a lunatic...

After reading the book, I somewhat agree with Dr. Alexandre: if the orthodontic profession does not evolve, it could disappear. I know orthodontists who are aware of this. But, they are only moderately worried as orthodontics is now changing at an accelerated rate: we now see treatments involving the use of miniscrews, Carriere Motion Appliance, MARPE, PAOO, sometimes combined with Invisalign - and the list goes on. The field of straightening teeth is certainly very different today from what it was only ten years ago.

Why should this concern us? Just like orthodontists, we need to change too. Our model needs to evolve, and it should start in our universities. If you think that dental sleep medicine is the frontier of our field, it certainly does not appear to be so, as most universities are teaching only traditional dentistry. Now is the time to be moving into the expanded concept of dental medicine. With a little less than 6000 new dentists joining the US work force in 2016 alone $^{2}$ and the prevalence of tooth decay steadily going down ${ }^{3}$, educators need to wake up quickly. The only good news I find is that the AADSM took upon itself to gather as many university professors in DSM as possible and allowed them to meet at their last annual meeting in Baltimore. I understand that this gathering will occur again at this year's annual AADSM meeting.

While many universities are slowly awakening to the need for crucial change, we as clinicians also need to improve our clinical expertise. If one looks back at the major review done by Ferguson et al. ${ }^{4} 13$ years ago and compares what was found then to the more recent studies on oral appliance therapy, the reduction of the apneahypopnia index (AHI) as a result of OAT has surprisingly not changed that much. Granted, we make better, sturdier, more hygienic and comfortable appliances now but in order to expand our field we also need to look elsewhere. One of the areas where we need to do better is case selection. At a time when the field of sleep medicine is undergoing significant changes, when even the value of the sacrosanct AHI index is being questioned $^{5}$, better case selection, by the use of precision medicine principles, could dramatically increase the success rate of OAT and give oral appliances the recognition they really deserve.

This is why I strongly invite you to have a look at Victor Lai, Dr. Jayne Carberry and Dr. Danny Eckert's paper in this issue of the $\mathrm{JDSM}^{6}$. They are providing us with a refreshing perspective on OSA. Their work is more than a glimpse into what our future is meant to be. Please note that Dr. Eckert will also be present at the AADSM annual meeting in San Antonio.

Of course, feel free to also read the rest of the issue as it is very good....

\section{CITATION}

Masse, JF. Will the orthodontic profession disappear? J Dent Sleep Med. 2019;6(2)

\section{REFERENCES}

1. Alexandre L. La guerre des intelligences. JC Lattès; 2017

2. Munson B, Vujicic M. Supply of full-time equivalent dentists in the U.S expected to increase steadily. American Dental Association. https://www.ada.org/ /media/ADA/Science\%20and\%20Research/ HPI/Files/HPIBrief_0718_1.pdf?la=en. Accessed April 3, 2019.

3. Centers for Disease Control and Prevention. Prevalence of total and untreated dental caries among youth: United States, 2015-2016. https://www.cdc.gov/nchs/products/databriefs/db307.htm. Accessed April 1, 2019. 
4. Ferguson KA, Cartwright R, Rogers R, Schmidt-Nowara W. Oral appliances for snoring and obstructive sleep apnea: a review. Sleep. 2006;29(2):244-62

5. Sutherland K, Almeida FR, de Chazal P, Cistulli PA. Prediction in obstructive sleep apnoea: diagnosis, comorbidity risk, and treatment outcomes. Expert Rev of Respir Med. 2018; 12(4):293307.

6. Lai V, Carberry JC, Eckert DJ. Sleep apnea phenotyping: Implications for dental sleep medicine. J Dent Sleep Med. 2019; 6(2).

\section{SUBMISSION AND CORRESPONDENCE INFORMATION}

\section{Submitted in final revised form March 31, 2019}

Address correspondence to: Jean-François Masse, Professor, Universite Laval, 2780 Masson \#200, Quebec City, QC, G1P 1J6, Canada; Tel: 418871-1447; Fax: 418-871-4983; Email: jean-

francois.masse@fmd.ulaval.ca 